\title{
ADEQUAÇÃO DE ENGATES RÁPIDOS DE ASPERSORES COMO CONECTORES DE MANGUEIRA PARA DISTRIBUIÇÃO DE ÁGUA EM SULCOS DE IRRIGAÇÃO ${ }^{1}$
}

\author{
FLAVIANE F. DE FARIA ${ }^{2}$, ROBERTO TESTEZLAF ${ }^{3}$
}

\begin{abstract}
RESUMO: Como forma de reduzir as perdas de água que ocorrem na irrigação empregada na cultura do tomateiro, agricultores vêm utilizando mangueiras de forma precária na distribuição de água aos sulcos. O presente trabalho teve como objetivo estudar a adequação de engates rápidos de aspersores para serem aplicados como conectores de mangueiras por produtores irrigantes que façam uso desse sistema de distribuição de água. A primeira etapa do estudo foi avaliar, em campo, a operacionalidade do uso de mangueiras por produtores que fazem uso desse sistema. Posteriormente, quatro modelos de engates rápidos, disponíveis no mercado, foram ensaiados em laboratório, determinando-se o coeficiente de resistência, o comprimento equivalente, a curva de perda de carga e a eficiência de estanqueidade. Como resultado, apresenta-se o projeto estrutural de um sistema de conexão de mangueiras, utilizando-se do modelo de engate com melhor desempenho e recomendações quanto ao seu uso na distribuição de água. Apesar da necessidade de ensaios adicionais em campo, o sistema proposto tem potencial para otimizar a eficiência do uso da água, melhorar as condições ergonômicas do trabalhador e garantir boa rentabilidade ao produtor.
\end{abstract}

PALAVRAS-CHAVE: equipamento de irrigação, eficiência do uso da água, tecnologia de irrigação.

\section{ADEQUACY OF QUICK COUPLER SPRINKLER AS HOSE CONNECTOR FOR WATER DISTRIBUTION IN FURROW IRRIGATION}

\begin{abstract}
As a way to reduce water losses in furrow irrigation systems, used in fresh market tomato production, farmers are improperly distributing water into the field using plastic hose. The objective of this work was to study the suitability of using quick coupler sprinkler as hose connectors for water distribution in tomato plantation. The first step of the study was to assess the current hose field operation for tomato growers. Subsequently, four models of quick couplers sprinklers available in the market were tested in laboratory to determine the coefficient of resistance, the equivalent tube length, the head loss curve and the linking efficiency. As result, a structural design for hose connectors was presented using the model of coupling with the best hydraulic performance. Additionally, some technical recommendations on its use in irrigation water distribution are highlighted. Despite the requirement for additional field trials, the proposed system has potential to optimize the water use efficiency, to improve workers ergonomic conditions, and ensure good profitability to the producer.
\end{abstract}

KEYWORDS: irrigation equipment, water use efficiency, irrigation technology.

\section{INTRODUÇÃO}

A irrigação por sulcos é a técnica predominantemente utilizada no Brasil, na produção de tomate de mesa, que é a segunda hortaliça em importância econômica e social no País. Essa técnica, quando mal manejada pelo agricultor, possui potencial para causar sérios impactos ambientais, reduzir a disponibilidade hídrica em bacias hidrográficas e comprometer a atividade econômica.

COLETTI (2005) estimou eficiência de aplicação de água na ordem de $26 \%$ para a irrigação por sulcos, em área comercial de produção de tomate de mesa, na região de Mogi Guaçu, sendo que

\footnotetext{
${ }^{1}$ Trabalho de iniciação científica do primeiro autor, financiado pelo Pibic/CNPq.

${ }^{2}$ Acadêmica de graduação, Faculdade de Engenharia Agrícola, FEAGRI/UNICAMP, Campinas - SP, Fone: (0XX19) 3521.2900, flaviane.faria@agr.unicamp.br

${ }^{3}$ Eng ${ }^{\circ}$ Agrícola, Prof. Titular, Faculdade de Engenharia Agrícola, FEAGRI/UNICAMP, Campinas - SP.

Recebido pelo Conselho Editorial em: 7-2-2007
}

Aprovado pelo Conselho Editorial em: 29-2-2008 
o baixo valor de eficiência no sistema estava associado às perdas por percolação, por escoamento superficial no canal secundário e na condução de água pelas tubulações. Uma das técnicas, já utilizadas por produtores, que buscam melhorar a operacionalidade e a eficiência de aplicação desses sistemas, é a utilização de mangueiras no abastecimento dos sulcos, o que pode contribuir para reduzir as perdas de água e garantir a minimização dos impactos adversos ao meio ambiente e, ainda assim, viabilizar economicamente a atividade.

GOMES (2005) afirma que o emprego de mangueiras na distribuição de água em sistemas de irrigação por sulcos é uma alternativa de fácil aceitação entre os tomaticultores devido ao fato de não exigir grandes mudanças na condução da cultura, demandar menor investimento inicial e menor custo de produção. Esse autor avaliou o sistema de distribuição de água e encontrou eficiência de aplicação superior a $80 \%$ e com menor custo de produção por ciclo da cultura em relação à irrigação por sulcos convencional e à irrigação por gotejamento. Nesse estudo, o sistema de irrigação com mangueiras garantiu a produtividade, a boa qualidade do produto e atendeu aos princípios de sustentabilidade, pois reduziu o volume de água (a lâmina de água utilizada na irrigação por sulcos com mangueira foi três vezes menor que a da irrigação por sulcos convencional), minimizou perdas por percolação e escoamento superficial, e reduziu impactos sobre o solo.

As áreas de cultivo que utilizam mangueiras na distribuição de água, caracterizam-se, geralmente, por empregar uma tubulação principal que conduz a água desde o reservatório até o local mais alto da produção. Dessa tubulação, derivam tubulações secundárias que possuem em seus finais válvulas de derivação de aço zincado utilizadas na irrigação por aspersão, onde são acopladas conexões adaptadas para receber somente uma mangueira de irrigação (Figura 1). O número de mangueiras que operam simultaneamente, depende da capacidade da motobomba, do número de conexões disponíveis e da disponibilidade de mão-de-obra na propriedade. Essa característica de manejo exige que o sistema de bombeamento opere fora de seu ponto de melhor eficiência, evidenciando a necessidade de buscar informações que auxiliem no aperfeiçoamento dessa técnica.

Outra característica desse sistema é que as mangueiras utilizadas são de polietileno de média densidade, com diâmetro de $38 \mathrm{~mm}$ e comprimento de $100 \mathrm{~m}$, exigindo cuidados em seu manuseio para evitar o surgimento de dobras que contribuiriam para a sua ruptura (Figura 2). Além de ser operado de forma totalmente empírica, o excesso de peso das mangueiras gera problemas de saúde aos trabalhadores rurais que passam turnos de 12 horas movimentando-as para cobrir a área irrigada dentro do turno de rega proposto pelo agricultor.

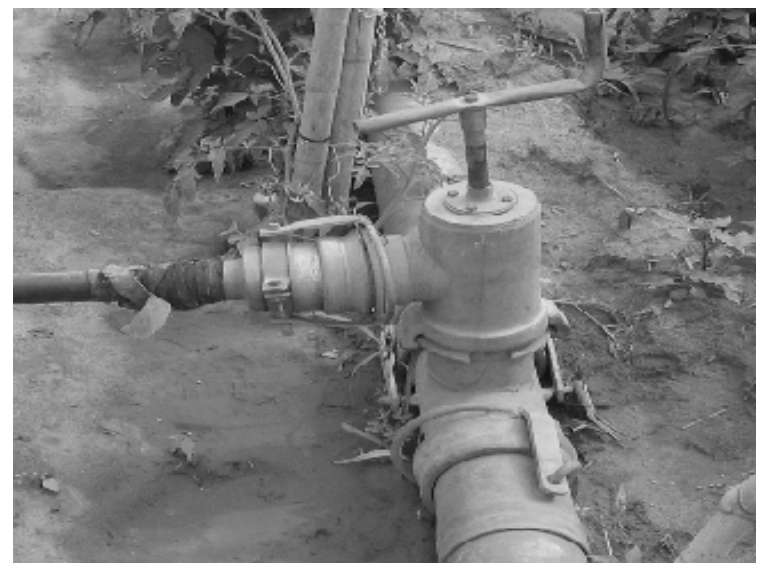

FIGURA 1. Adaptação de conexão de mangueira utilizada na cultura do tomate de mesa. Example of current hose connection adapted by fresh market tomato growers.

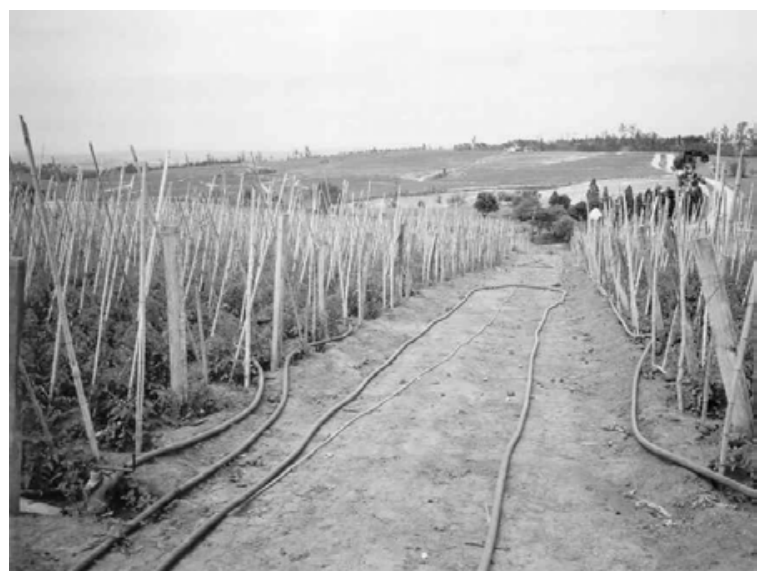

FIGURA 2. Disposição de mangueiras de irrigação operando em uma propriedade. Irrigation hose arrangements in a farm operation. 
Dessa forma, buscando dar continuidade aos estudos de novas tecnologias de irrigação na tomaticultura de mesa e contribuir com informações que auxiliem o uso apropriado da técnica de irrigação por sulcos abastecidos por mangueira, o presente trabalho teve como objetivos avaliar a adequação de engates rápidos de aspersores como conectores de mangueiras e apresentar o projeto estrutural de um engate rápido de mangueiras que facilite o manejo da técnica em questão, otimizando a eficiência do uso da água e melhorando as condições ergonômicas do trabalhador, a partir de materiais acessíveis, economicamente, a todos os produtores.

\section{MATERIAL E MÉTODOS}

\section{Diagnóstico do uso de mangueiras na irrigação por sulcos}

Com o objetivo de desenvolver uma proposta de acoplamento rápido de mangueiras para utilização na distribuição de água em sistemas de irrigação por sulcos na tomaticultura de mesa, iniciou-se este estudo, com avaliação de campo, para a utilização de mangueiras por produtores que já fazem uso desse sistema com conexões adaptadas. Com o intuito de conhecer as dificuldades da sua aplicação e levantar parâmetros de seleção desse acessório, foram realizadas entrevistas de campo com trabalhadores e proprietários em duas propriedades produtoras de tomate de mesa da região de Campinas: uma localizada em Indaiatuba - SP (Produtor A), e outra em Monte Mor - SP (Produtor B). Essas propriedades foram escolhidas por representarem adequadamente os produtores que utilizam o sistema de irrigação por mangueiras na região de Campinas - SP. Utilizando-se de um questionário técnico, obteve-se informação sobre o manejo de irrigação, identificando as principais facilidades e dificuldades encontradas pelos trabalhadores, além de analisar os tipos de conexões e mangueiras utilizadas em campo.

\section{Seleção de engates e conexões}

Realizou-se levantamento dos principais tipos de conexões e engates rápidos existentes no mercado, permitindo relacionar as principais empresas fabricantes desse tipo de material e obter maiores informações técnicas sobre esses acessórios. Foram adquiridos quatro tipos de engates rápidos utilizados em conexões de aspersores de baixa e média pressão de serviço que apresentavam potencial para serem adaptados como conexão rápida de mangueiras. Na Tabela 1, apresentam-se as principais dimensões e características dos engates pesquisados.

TABELA 1. Características dimensionais e do sistema de travamento e acionamento dos engates avaliados. Dimensional characteristics of the lock system and type of latch for the evaluated couplings.

\begin{tabular}{cccccc}
\hline Engate & $\begin{array}{c}\text { Diâmetro de } \\
\text { Entrada }(\mathrm{m})\end{array}$ & $\begin{array}{c}\text { Diâmetro } \\
\text { de Saída } \\
(\mathrm{m})\end{array}$ & $\begin{array}{c}\text { Sistema de } \\
\text { Travamento } \\
\text { (parte macho) }\end{array}$ & $\begin{array}{c}\text { Sistema de } \\
\text { Acionamento da } \\
\text { Mola }\end{array}$ & $\begin{array}{c}\text { Tipo de Acoplamento } \\
\text { de Mangueira }\end{array}$ \\
\hline 1 & 0,0254 & 0,0254 & Interno & Indireto & Interno \\
2 & 0,0254 & 0,0191 & Externo & Direto & Externo \\
3 & 0,0254 & 0,0254 & Externo & Indireto & Interno \\
4 & 0,0254 & 0,0254 & Interno & Indireto & Interno \\
\hline
\end{tabular}

Na Tabela 1, os engates são identificados pelas características relacionadas ao sistema de travamento do engate, ao sistema de acionamento da mola e ao acoplamento de mangueira. A caracterização do sistema de acionamento da mola indica se o acoplamento (macho da peça) aciona a mola diretamente ou se há outra peça intermediária que aciona a mola. Já o tipo de acoplamento da mangueira refere-se ao tipo de rosca presente no macho da peça onde se conecta a mangueira (rosca interna ou externa).

Na Figura 3, apresentam-se os desenhos dos engates pesquisados. Os quatro engates possuem uma base, que é rosqueada à tubulação e denominada parte fêmea do acessório, e um acoplamento superior, responsável pelo acoplamento rápido da mangueira, denominado parte macho do engate. A parte fêmea contém uma válvula de vedação, que é responsável pela liberação, ou não, da passagem de água pela peça. 


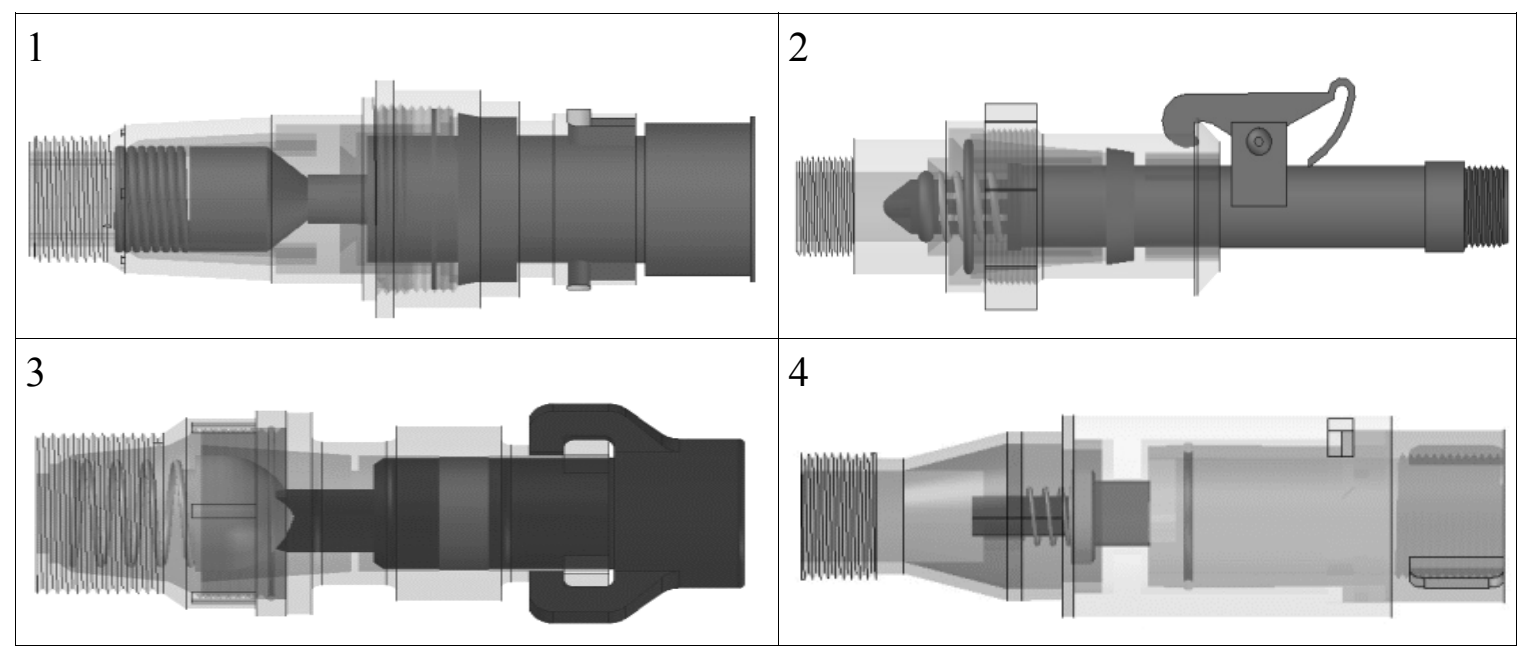

FIGURA 3. Desenhos dos modelos de engates rápidos avaliados. Drawings of the evaluated quick couplers.

\section{Avaliação técnica dos engates}

Buscando parâmetros que auxiliassem no projeto de nova conexão, avaliou-se uma peça de cada engate, visando a conhecer o desempenho hidráulico dos materiais (engate e mangueira). Foram realizados ensaios de perda de carga e estanqueidade, verificando-se, também, as vantagens e as desvantagens apresentadas pelos engates em relação ao sistema de travamento.

- Estudo de perda de carga dos engates

No Laboratório de Hidráulica da Faculdade de Engenharia Agrícola, foi montada uma bancada de ensaio para a determinação da curva de perda de carga dos engates (Figura 4), constituída basicamente de: reservatório de água; conjunto motobomba marca Mark, modelo D58; válvula reguladora de pressão marca Doroty; dois registros tipo gaveta; manômetro de Bordon com válvula de duas vias e tomada de pressão; tubulação de PVC (DN 40), e hidrômetro digital marca GPI. As localizações das tomadas de pressão à jusante e a montante do engate respeitaram a distância mínima de dez vezes o diâmetro da tubulação para garantir o pleno desenvolvimento do escoamento.

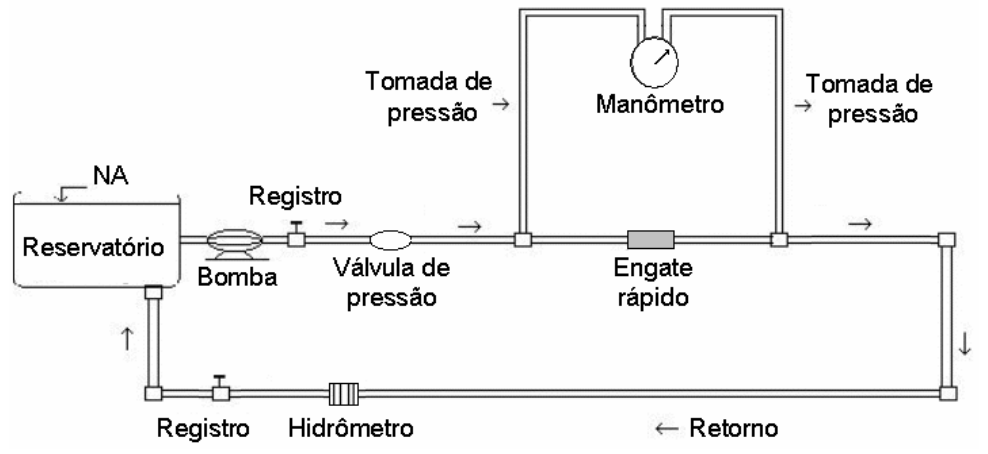

FIGURA 4. Bancada de ensaio de perda de carga. Head loss experimental apparatus.

Cada ensaio foi iniciado, ligando o conjunto motobomba e abrindo lentamente os registros para que o circuito hidráulico entrasse em regime de operação. A partir de vazões predefinidas, coletaram-se as respectivas pressões antes e depois de a água passar pelo engate. A perda de carga foi obtida pela diferença de pressão entre os dois pontos.

Para cada engate, determinou-se a perda de carga experimental para valores de vazão definidos por três procedimentos de ensaios. Nos dois primeiros ensaios, mediu-se a perda de carga em faixa de vazão entre 0,5 e $5,0 \mathrm{~m}^{3} \mathrm{~h}^{-1}$ com incrementos de aproximadamente $0,5 \mathrm{~m}^{3} \mathrm{~h}^{-1}$, sendo 
que a primeira medida foi realizada diminuindo-se a vazão, e a segunda, aumentando-se a vazão. No terceiro ensaio, a perda de carga foi determinada para valores aleatórios de vazões.

Substituindo os valores experimentais de velocidade e de perda de carga na eq.(1) (AZEVEDO NETTO et al., 1998), obtiveram-se os valores correspondentes da constante K de cada engate.

$$
\mathrm{Hf}=\mathrm{K} \frac{\mathrm{v}^{2}}{2 \mathrm{~g}}
$$

em que,

Hf - perda de carga no engate, $\mathrm{m}$;

$\mathrm{K}$ - coeficiente de resistência da válvula ou união, adimensional;

$\mathrm{v}$ - velocidade média da tubulação, $\mathrm{m} \mathrm{s}^{-1}$, e

$\mathrm{g}$ - aceleração da gravidade, $\mathrm{m} \mathrm{s}^{-2}$.

A partir dos valores médios de $\mathrm{K}$ para cada engate, determinaram-se os respectivos valores do comprimento equivalente pela eq.(2).

$$
\text { Leq }=\frac{K D}{f}
$$

em que,

f - coeficiente de atrito (adimensional), calculado a partir do diagrama de Moody;

$\mathrm{D}$ - diâmetro do conduto, $\mathrm{m}$, e

Leq - comprimento equivalente da tubulação, $\mathrm{m}$.

O coeficiente de atrito (f) foi obtido a partir do Ábaco de Moody, utilizando-se da viscosidade cinemática da água $v=110^{-6} \mathrm{~m}^{2} \mathrm{~s}^{-1} \mathrm{e}$ da rugosidade absoluta do polietileno igual a $0,001 \mathrm{~mm}$. As médias dos valores de f utilizados foram 0,02 para os engates $1 ; 2$ e 4, e 0,03 para o engate 3 .

As curvas de perda de carga de cada engate rápido foram geradas a partir da eq.(1), utilizando-se do valor médio de $\mathrm{K}$.

- Estanqueidade dos engates

A partir da norma NBR 9811 (ABNT, 1987), realizaram-se os ensaios de estanqueidade, utilizando-se da mesma bancada dos ensaios de perda de carga. Estando o circuito hidráulico em regime de escoamento estabilizado, elevou-se a pressão de 49,0 kPa até $245,2 \mathrm{kPa}$, medindo-se a taxa de vazamento (volume/tempo) de água dos engates para pressões de 49,0 $\mathrm{kPa} ; 98,1 \mathrm{kPa}$; $147,1 \mathrm{kPa} ; 196,1 \mathrm{kPa}$ e 245,2 kPa, utilizando-se de proveta e de cronômetro.

Após o ciclo de elevação da pressão, essa variável foi mantida constante no valor de $196,1 \mathrm{kPa}$, sendo realizadas as seguintes operações manualmente: forçou-se verticalmente para cima a parte macho do engate e observou-se a ocorrência de vazamentos; girou-se o conjunto a partir da extremidade da parte macho do engate e observou-se a ocorrência de vazamentos.

A estanqueidade das partes que compõem o engate, também foi observada, desconectando-se a parte macho dos engates a uma pressão de $147,1 \mathrm{kPa}$ e verificando-se a ocorrência de vazamentos da parte fêmea dos engates, identificando-se, também, as facilidades e as dificuldades do sistema de travamento dos engates a essa pressão.

\section{Projeto do engate}

A partir dos resultados dos ensaios dos engates, desenvolveu-se proposta de projeto estrutural de conexão a ser utilizada pelos tomaticultores. A partir das características operacionais das propriedades visitadas, foram propostas recomendações quanto à quantidade de conexões a serem utilizadas em campo, diâmetro e comprimento da mangueira. 


\section{RESULTADOS E DISCUSSÃO}

\section{Diagnóstico do uso de mangueiras na irrigação por sulcos}

As duas propriedades visitadas utilizavam manejos de irrigação semelhantes, com tempo médio de irrigação de 16 horas semanais, sendo o momento da irrigação determinado de acordo com a experiência do proprietário, sem ajuda de nenhuma tecnologia. Ambas as lavouras empregavam um trabalhador braçal por mangueira de irrigação, e cada mangueira abastecia duas quadras da cultura. Esse trabalhador colocava a mangueira em um sulco e somente mudava a posição para outro sulco depois que a frente de avanço da água atingisse o seu final.

Os produtores afirmaram que a utilização de mangueiras é mais fácil que o antigo manejo de irrigação, na qual se utilizavam "bandeiras" para desviar a água nos sulcos. De acordo com os trabalhadores, o uso de mangueiras exige maior esforço na hora de movimentá-la para o início do carreador ou do talhão, devido ao seu comprimento, sendo necessária a ação de dois trabalhadores. Adicionalmente, durante o evento da irrigação, existia a dificuldade para um único trabalhador mover a mangueira na mudança do talhão devido ao seu peso, fato confirmado pelas queixas constantes de dores nas costas e na coluna vertebral pelos trabalhadores.

Outra ocorrência notada nas propriedades visitadas é que, devido ao fato de a vazão utilizada na irrigação ser inferior à capacidade do sistema motobomba, os agricultores reduziam a vazão do sistema por meio do fechamento do registro ou pela redução da aceleração dos motores. Adicionalmente, a utilização de uma única mangueira em cada talhão aumenta o tempo de irrigação e o tempo de operação da bomba, implicando maiores gastos com energia.

- Estudo de perda de carga

A partir dos dados obtidos no ensaio de perda de carga, determinaram-se os valores de $\mathrm{K}$ para os quatro modelos de engates rápidos. Os gráficos do coeficiente de resistência, em função do número de Reynolds, são apresentados na Figura 5.

Engate 1

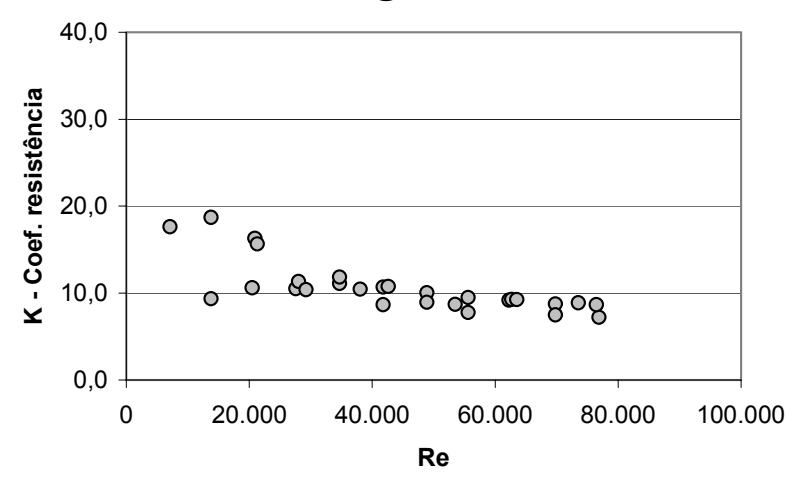

Engate 3

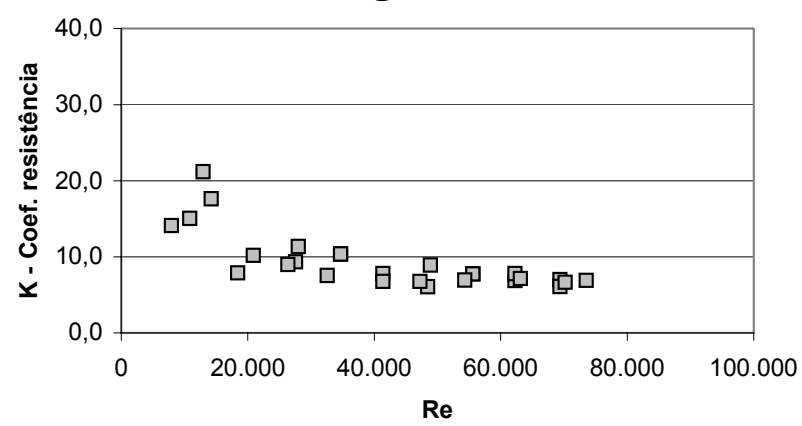

Engate 2

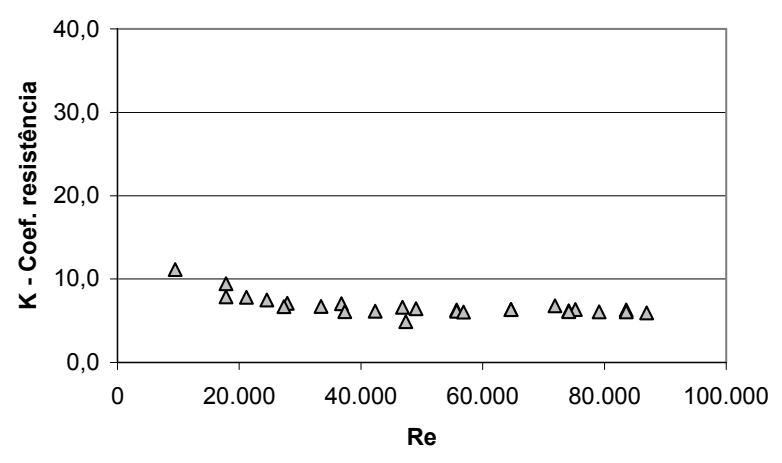

Engate 4

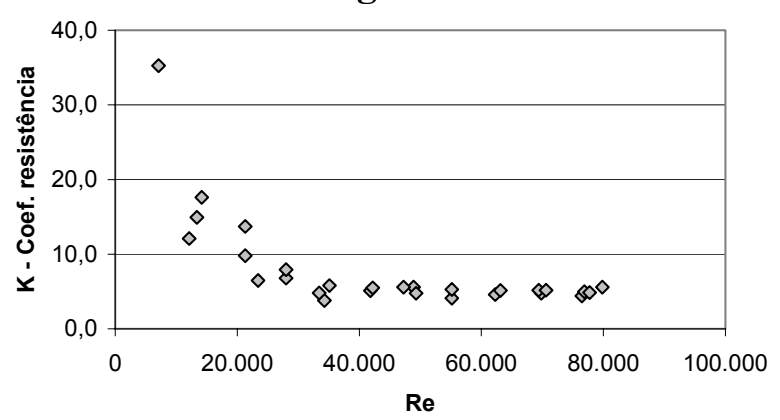

FIGURA 5. Coeficiente de resistência (adim) em função do número de Reynolds (adim) para os engates avaliados. Curves of the resistant coefficient versus Reynolds Number for the evaluated quick couplers. 
Observa-se, nos gráficos da Figura 5, que a maior variabilidade nos valores do coeficiente de resistência para os quatro modelos ensaiados ocorreu para valores do número de Reynolds inferiores ou próximos de 20.000, ou seja, para baixos valores de velocidade. Para números de Reynolds acima de 20.000 , existe a tendência de redução da dispersão e do valor de $\mathrm{K}$ atingir valor constante.

$\mathrm{Na}$ Tabela 2, apresentam-se os valores médios de $\mathrm{K}$ para cada engate com o respectivo desvio-padrão e coeficiente de variação, e os correspondentes valores de comprimento equivalente (Leq).

TABELA 2. Valores médios do coeficiente de resistência, desvio-padrão, coeficiente de variação e comprimento equivalente dos engates ensaiados. Average values of the resistant coefficient, standard deviation, coefficient of variation and length equivalent to the tested couplings.

\begin{tabular}{ccccc}
\hline Engate & K (adim) & DP (adim) & C.V. $(\%)$ & Leq $(\mathrm{m})$ \\
\hline 1 & 10,6 & 2,9 & 27,7 & 13,5 \\
2 & 6,8 & 1,2 & 17,9 & 6,5 \\
3 & 9,3 & 3,7 & 39,8 & 7,9 \\
4 & 7,8 & 6,4 & 82,0 & 9,9 \\
\hline
\end{tabular}

Dentre os engates ensaiados, o modelo 2 foi o que apresentou o menor valor do coeficiente de resistência e comprimento equivalente, proporcionando, também, o menor coeficiente de variação. Observa-se, também, que o modelo 1 alcançou o maior valor do coeficiente de resistência, e o modelo 4, o maior valor de coeficiente de variação.

Para efeito de análise, podem-se comparar os valores da Tabela 2 com os valores apresentados por NEVES (1960). Esse autor apresentou valores de K para registros e válvulas com diferentes graus de abertura para o escoamento, recomendando $\mathrm{K}=0,07$ para a relação de $7 / 8$ entre a seção de passagem de água e a seção total; $\mathrm{K}=5,52$ para a relação de $3 / 8 ; \mathrm{K}=17$ para a relação de $1 / 4$, chegando ao valor de 97,8 para a relação de 1/8. TESTEZLAF (1982) obteve $\mathrm{K}=4,11$ e Leq = 9,32 m para válvulas de gaveta de 1,5" com cinco voltas fechadas; $\mathrm{K}=22,47$ e Leq $=50,96 \mathrm{~m}$ na posição de sete voltas fechadas, em que 9,5 voltas correspondem ao registro totalmente fechado. Comparando com os valores da literatura, pode-se afirmar que valores médios de $\mathrm{K}$ obtidos para os engates avaliados são consistentes.

A partir do valor médio de $\mathrm{K}$ para cada engate e da eq.(1), obteve-se a curva da perda de pressão dos engates (Figura 6).

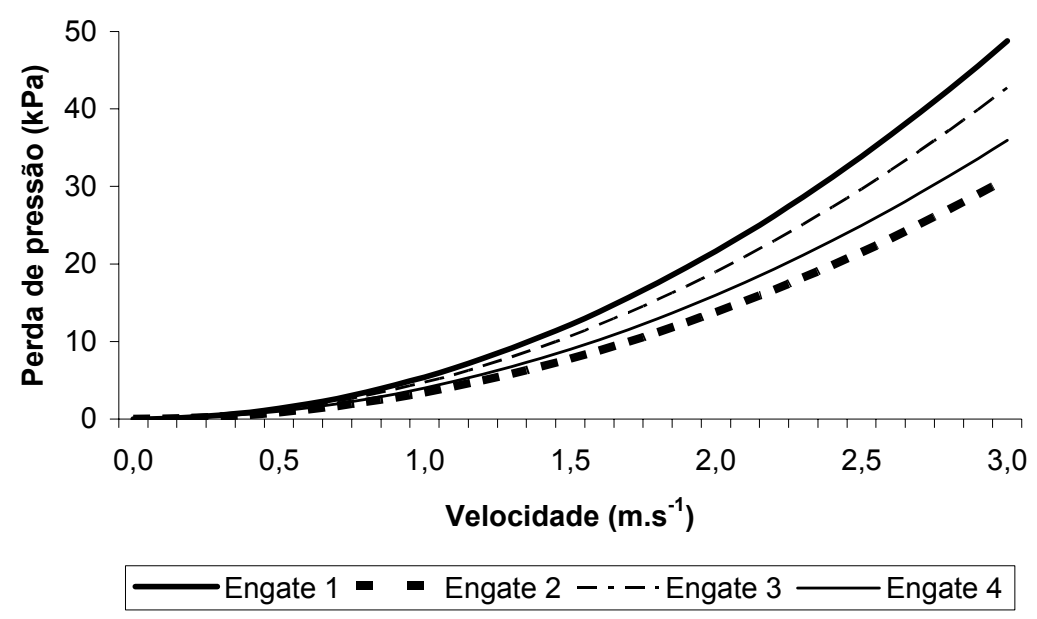

FIGURA 6. Curva de perda de pressão para os engates avaliados. Head loss curves for the evaluated quick couplers. 
A partir da Figura 6, verifica-se que o engate 2 apresentou os menores valores de perda de pressão em função da velocidade de escoamento entre os engates ensaiados, e o engate 4 apresentou valores ligeiramente superiores ao engate 2. Os comportamentos apresentados pelos engates estão de acordo com os valores encontrados para os respectivos coeficientes de resistência.

A menor perda de pressão apresentada pelo engate 2 pode ser explicada pela estrutura interna diferenciada de acionamento da mola do acessório. Nesse engate, a mola, que está localizada na parte posterior da ponteira cônica, é acionada diretamente pela parte macho do engate, enquanto nos outros engates a mola se posiciona na parte anterior da ponteira, forçando o fluxo de água pela parte frontal da ponteira do núcleo da válvula. Outras características do engate 2 que podem ser responsáveis por esse resultado, é que esse engate apresenta perfeito alinhamento de suas peças e válvula de vedação constituída de mola rígida e ponteira do tipo cônica.

Para a velocidade de $3 \mathrm{~m} \mathrm{~s}^{-1}$, a perda de pressão experimental do engate $1(48,7 \mathrm{kPa})$ apresentou-se próxima ao valor fornecido pelo fabricante $(58,8 \mathrm{kPa})$. Já o engate 2 , para essa mesma velocidade, apresentou perda de pressão $(31,0 \mathrm{kPa})$ significativamente superior ao valor fornecido pelo fabricante $(14,0 \mathrm{kPa})$. Para os engates 3 e 4, não foi possível realizar essa comparação porque os fabricantes não possuíam informações de perda de pressão de seus produtos.

\section{- Estanqueidade dos engates}

Os engates 1 e 2 não apresentaram vazamento, enquanto o engate 3 apresentou valores de taxa de vazamento em torno de $0,012 \mathrm{~L} \mathrm{~h}^{-1}$. $\mathrm{O}$ engate 4 apresentou taxa média de vazamento de $2,16 \mathrm{~L} \mathrm{~h}^{-1}$, indicando que esse engate não garante boa estanqueidade do sistema.

Os engates 1; 3 e 4 apresentam sistema de travamento desvantajoso pela necessidade de torção da parte macho do engate, fator que pode levar à freqüente torção da mangueira e, com isso, à diminuição de sua vida útil. Além disso, o engate 1 apresentou maior facilidade de desengate.

$\mathrm{O}$ engate 2 , diferentemente dos demais engates, possui sistema de trava externo que permite o rápido e fácil acoplamento por meio de gancho que se prende à parte fêmea do engate, e ainda possui sistema direto de acionamento da mola que proporciona melhor estanqueidade.

\section{Proposta de conexão de mangueiras}

A partir dos resultados obtidos nos ensaios, desenvolveu-se uma proposta de projeto estrutural para a conexão de mangueiras baseada no engate 2, devido ao modelo ter apresentado melhor desempenho nos testes realizados, tendo menor perda de carga, menor Leq, melhor sistema de travamento e boa estanqueidade. Nas Figuras 7 e 8, estão apresentados os esquemas da conexão de mangueiras projetadas.

Ao invés de ter a ponta macho rosqueável, padrão para uso em aspersores, a conexão proposta possui uma união de mangueiras nessa parte. Optou-se, nesse momento, para um diâmetro de entrada da conexão de $25,4 \mathrm{~mm}$ e de saída de $19,0 \mathrm{~mm}$, sendo que somente após levantamento das dimensões de mangueiras disponíveis no mercado é que se devem definir os valores dessas dimensões.

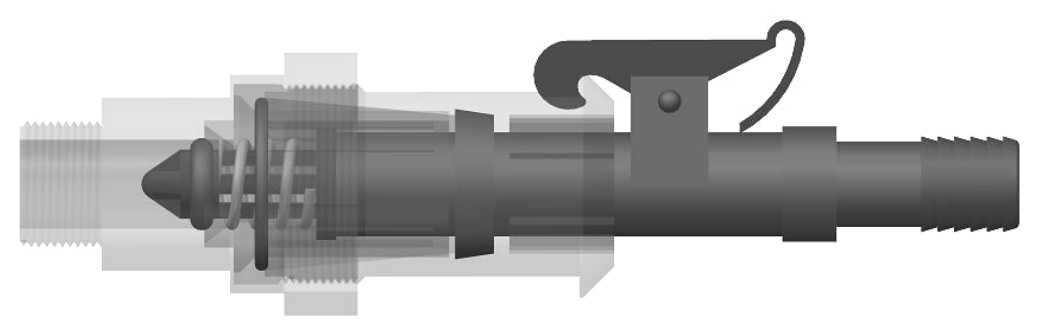

FIGURA 7. Esquema da conexão de mangueiras montadas. Drawing of the assembled hose coupling. 


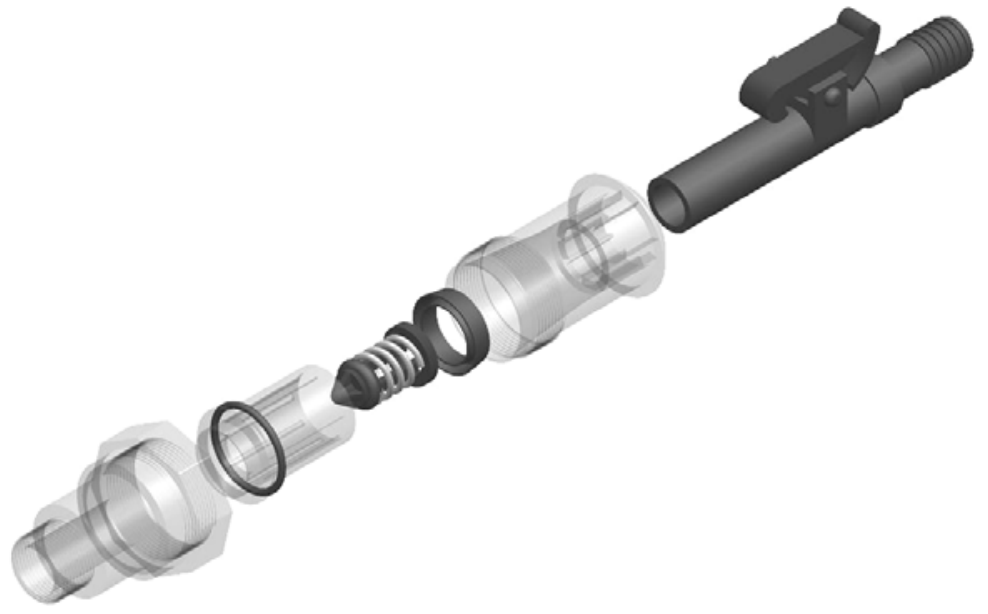

FIGURA 8. Detalhe das peças constituintes da conexão de mangueiras. Details of the constituent parts of hose coupling.

Na Figura 9, apresenta-se a montagem de duas conexões que possibilitam o acoplamento de duas mangueiras que podem operar simultaneamente, ou não. As conexões rápidas estão unidas por uma peça "T", com diâmetro de 0,254 $\mathrm{m}$ (1"), que liga os engates à tubulação principal do sistema de irrigação.

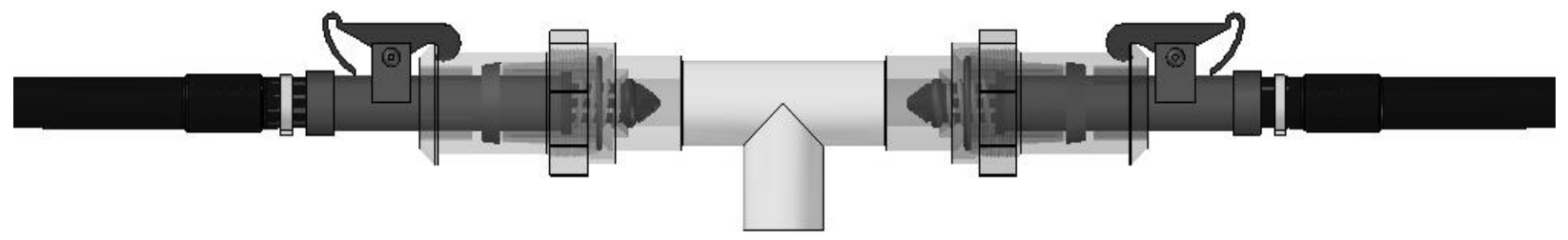

FIGURA 9. Esquema para montagem de uma conexão para duas mangueiras. Outline of the connecting assembling for two hoses

Este trabalho indicou o engate rápido de aspersores com melhores condições hidráulicas para ser utilizado como conexão de mangueiras, exigindo somente mudança na tubulação de entrada do acessório. Entretanto, é necessário enfatizar que a viabilidade final do uso do engate exigirá outras avaliações em campo que permitam analisar a operacionalidade da proposta e que também envolva a questão de durabilidade da conexão quando em uso intenso por agricultores.

\section{Proposta de operação do sistema}

Devido às dificuldades de operação do sistema apresentadas pelos agricultores e visualizadas no campo, apresenta-se aqui, como exemplo, uma proposta de operação conjunta de, no mínimo, duas mangueiras de $30 \mathrm{~m}$ de comprimento. Esse comprimento facilitaria o deslocamento da mangueira até o início do carreador, podendo esse trabalho ser realizado por apenas uma pessoa.

Como nas propriedades visitadas a capacidade de bombeamento era maior que a vazão utilizada na irrigação, os agricultores eram obrigados a reduzir a vazão da motobomba, seja por meio do fechamento do registro, seja por redução da aceleração dos motores. Nesses casos, é possível recomendar a utilização de duas mangueiras, permitindo irrigar dois sulcos simultaneamente, diminuir o tempo de mão-de-obra e o tempo de operação da bomba. Entretanto, se o comprimento das mangueiras for limitado a $30 \mathrm{~m}$, é necessário maior número de conexões adaptados à tubulação principal. Assim, as conexões duplas deveriam localizar-se a cada $60 \mathrm{~m} \mathrm{e}$ atender a 50 sulcos, considerando-se que, na tomaticultura, o espaçamento médio entre linhas é de 1,2 m (Figura 10). 


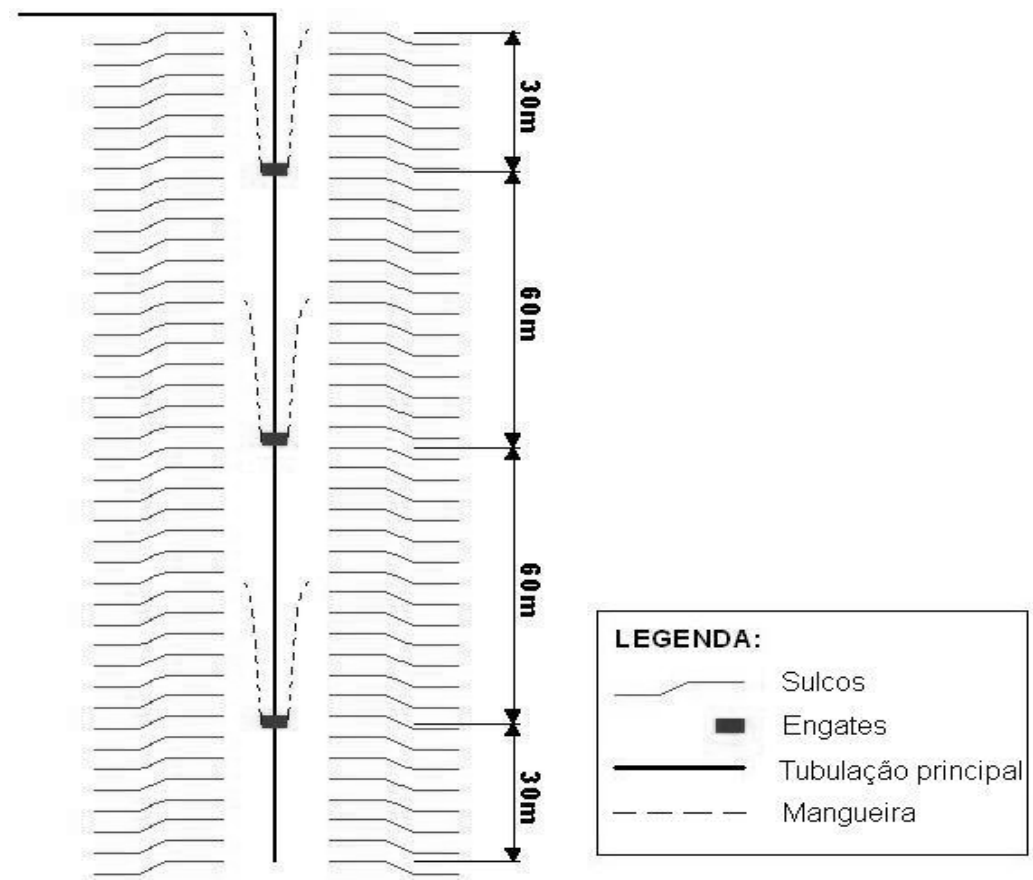

FIGURA 10. Esquema do sistema de irrigação para mangueiras com $30 \mathrm{~m}$. Irrigation system arrangement for $30 \mathrm{~m}$ length hoses.

\section{CONCLUSÕES}

A partir de quatro modelos de engates rápidos utilizados, foi proposto, neste trabalho, um projeto estrutural de conexão para mangueiras que poderá ser utilizado na distribuição de água em sistemas de irrigação por sulcos. A proposta de conexão foi desenvolvida a partir do modelo de engate rápido que melhor atendeu aos princípios do projeto, apresentando menor perda de carga, menor Leq, sistema de travamento adequado e boa estanqueidade.

Apesar de ser necessária a construção de um protótipo da conexão e avaliá-lo em campo, é possível afirmar que, dentro da proposta de sua utilização com duas mangueiras por acoplamento, o acessório tem potencial para oferecer melhores condições ergonômicas ao trabalhador, aumentar a eficiência do sistema e diminuir o tempo gasto com essa atividade pelo trabalhador.

\section{AGRADECIMENTOS}

Ao CNPq/Pibic, pela concessão da bolsa de iniciação científica; ao Eng ${ }^{0}$ Túlio A. P. Ribeiro e ao graduando Marcos Paulo de Freitas, pela colaboração nos ensaios realizados em laboratório.

\section{REFERÊNCIAS}

ASSOCIAÇÃO BRASILEIRA DE NORMAS TÉCNICAS. NBR 9811: Junta elástica de engate rápido de tubos de alumínio PN 80 para irrigação - verificação do desempenho, 1987.6 p.

AZEVEDO NETTO, J.M.; FERNANDEZ Y FERNANDEZ, M.; ARAUJO, R.; ITO, A. E. Manual de hidráulica. 8.ed. São Paulo: Edgard Blucher, 1998. 120 p.

COLETTI, C. Impactos do uso da irrigação por sulcos na cultura do tomateiro sobre a disponibilidade hídrica da bacia hidrográfica do Rio das Pedras, Mogi Guaçu - SP. 2005.164 f. Tese (Doutorado em Água e Solo) - Faculdade de Engenharia Agrícola, Universidade Estadual de Campinas, Campinas, 2005.

GOMES, E.P. Viabilidade de mudanças tecnológicas na irrigação da tomaticultura de mesa. 2005. 96 f. Tese (Doutorado em Água e Solo) - Faculdade de Engenharia Agrícola, Universidade Estadual de Campinas, Campinas, 2005. 
NEVES, E.T. Curso de hidráulica. 2.ed. Porto Alegre: Ed. Globo, 1968. 185-249 p.

TESTEZLAF, R. Estudo de perda de carga em tubulações e engates rápidos utilizados em linhas de irrigação. 1982. 97 f. Dissertação (Mestrado em Engenharia Agrícola) - Faculdade de

Engenharia de Alimentos e Agrícola, Universidade Estadual de Campinas, Campinas, 1982. 